\title{
Surveillance, transparency, \\ and trust
}

\section{Critical challenges from the COVID-I9 pandemic}

\section{David Lyon}

\section{Introduction}

It is no exaggeration to say that the issues of surveillance, transparency, and trust have never been as important as in the early twenty-first century. This bold assertion rests on the observation that today's complex global condition is the product of a heady-some would say toxic-mix of technological, social, economic, political, and cultural change. We inhabit a global world of high technology — the digital — in which major corporations vie for supremacy, challenging conventional nation-states and their varying "democracies," which are themselves simultaneously buffeted by new authoritarian nationalisms and the negative consequences of globalization.

Surveillance has become an everyday feature of social, economic, and political life in the twenty-first century. At an infrastructural level, the systems for organizing daily life are data dependent and surveillant. This has occurred faster than the development of appropriate norms and legal instruments for ensuring that surveillance is practiced for the common good (Stoddart 2021), including data justice based on trust, especially between state and citizen and corporation and consumer.

The unwelcome insertion of the coronavirus pandemic has sharpened debates over precisely these issues (French and Monahan 2020). At every level, COVID-19 exacerbates the acute threats to both person and planet, across various dimensions. Responses are overwhelmingly reliant on digital systems and devices, in a multitude of ways. This is not surprising; the pandemic was the first to occur in a context of developed platform companies, and it inspired imaginative digital responses. However, the lack of common regulation, along with resistance to government restrictions on the part of some large corporations, makes for an ambiguous situation, the consequences of which will be debated for years to come (Lyon 2021).

On the one hand the pandemic prompted a wholesale shift to remote working for millions of people, where feasible, and the massive global reliance on many highly surveillant platforms for communication, education, entertainment, and business. On the other is the huge array of digital devices 
and systems for combating the effects of the virus, from ubiquitous contacttracing apps to enhanced health data platforms for tracking its spread and distribution. Surveillance capitalism - the monetization of personal data by platform companies - is implicated in each.

Throughout 2020, state and corporate surveillance capacities were rapidly enhanced in many countries around the world. There was unprecedented pandemic-propelled growth in data gathering, analysis, and use, which within a few months had affected literally billions of people. China and India - with their huge populations - were among the many nations that expanded their ability to probe details of citizens' lives and made participation in smartphone-based schemes to obtain such data mandatory. Countries with small populations, such as Israel/Palestine or Iceland, also joined the COVID-19 surveillance rush to rapidly establish strengthened health data systems and to seek innovative digital applications designed to warn everyday smartphone users if they had been near a possibly infected person.

The global pandemic also inspired much welcome innovation in medical treatment and hospital care as well as numerous attempts to learn about and check the spread of the virus. These include multiple surveillance responses to COVID-19 as a public health condition. Such initiatives included efforts to chart the spread of the virus, to learn which geographical areas and population groups were the most vulnerable, and to allow as many people as possible to contribute meaningfully to reducing the ravages of contagion. The collection and curation of data were, however, not always accompanied by adequate explanations of how, why, and with what implications those data were being used for profiling and predicting or what expectations citizens could have about issues such as data protection and privacy. Transparency was often lacking and trust was eroded. In the Indian state of Kerala, for instance, legal objections were raised about the threat to civil liberties of the mandatory phone app.

At the same time, the surveillance responses to COVID-19 as a social condition have also been enormous and at the time of writing are also ongoing. There is a worldwide plethora of new surveillance initiatives - responding to developments such as working, shopping, and learning from home - that have been appearing with great rapidity but have been less in the limelight than those relating directly to the pandemic. Remote monitoring and policing of employees, urban residents, and students, along with enhanced routine commercial surveillance of consumers, is booming. These systems and devices are touted as supposed "solutions" to the social condition of a health emergency but, despite being inherently surveillant, are under even less ethical and legal scrutiny than usual. Yet their production bodes ill for those who care about the long-term consequences of the pandemic. Accountability for such innovations is often minimal to nonexistent (Deibert 2020).

Back in 2001, a perceived crisis of national and international security was prompted by the attacks on Washington and New York, and these were met 
by a similar explosion of concern to find digital means of predicting and preventing terrorism. Although much was clear about the massively increased scope of US national security at the time - it affected many others globally, not least through air transportation requirements - it was not until the muchpublicized disclosures by Edward Snowden in 2013 that the enormous reliance on so-called open-source data-that is, largely from social media-became clear. These prompted major, international queries about transparencywho knew? - and trust in relation to security-surveillance data (Lyon and Murakami Wood 2020, Laidler this volume).

But if that was true of $9 / 11$ then how much more is the wholesale move to digital technologies evident in the global coronavirus pandemic that began in 2019? The Economist commented on the rapid growth of a "Coronopticon" as early as March 2020. While noting the need for urgent attention to be paid to the origins and spread of the disease, with a view to its containment, they did observe that many countries were using an array of apps and data systems to keep tabs on the pandemic - "and also, in the process, on their citizens" (The Economist 2020). While the emerging structure surpasses in multiple ways the unidirectional transparency of Bentham's 1791 "panopticon" prison diagram, certain similarities not mentioned in the The Economist briefing do bear mentioning.

First of all, it is clear that, as with so many apps and systems, those built or modified for the pandemic aspire to make the lives of ordinary citizens visible to the organizations that produce or use the technology, while little or no attention is paid to ensuring the transparency of the apps or systems to their subjects. Secondly, the reliance on digital technologies is often achieved through very close collaboration between government health departments and platforms along with private corporations. Public health tasks were often outsourced to private companies, with little oversight or accountability, either for completing tasks effectively or for safeguarding civil liberties or privacy. This also extends into other areas such as employment, commerce, and education. It is often unclear - think of the noteworthy case of the Google-Apple API offered for contact-tracing worldwide - exactly how government regulation applies or how these businesses are handling or storing data. This challenges notions of trust, in both business and government. Thirdly, the very framing of these emergency initiatives suggests a purely utilitarian spirit, much like that which energized Bentham in his quest for the greatest happiness of the greatest number. In the case of the pandemic, the emphasis is often on a calculus of how many deaths are acceptable in the effort to balance public health with economic dynamism.

In what follows, we shall examine these issues in more depth, with a view to considering the complex challenge of agency for human flourishing. This in turn depends on transparency and trust, each of which is threatened by many kinds of surveillance but which themselves require better definition and practical application. Why focus on flourishing? Because all too often the weight 
of technological development and public policy pulls the questions down to the level of technocratic and deterministic criteria. To assert a need for considerations of human agency and flourishing is ambitious, of course, but as many contributions to these debates demonstrate, there is a crying need for ways to lift familiar constructions of the situation to a higher level.

\section{Pandemic surveillance: transparency and trust}

Since the late twentieth century, surveillance has grown exponentially-I choose these words carefully - in tandem with the development of digital technologies. Watching, monitoring, and tracking have shifted, in less than half a century, from being targeted and operated within specific siloes such as policing, workplace management, and government administration, to something experienced in everyday life as an unremarkable occurrence. Whereas machines such as video cameras were once placed where they might capture images as people pass by, we now see smartphones carried in personal pockets and bags that constantly record the time and place of communications and transactions between identifiable individuals, such that they may be mapped and traced. Of course, the surveillance cameras are still present, now enhanced by facial recognition technology, and are used by countries such as China, India, Russia, and South Korea to help enforce pandemic quarantines (Roussi 2020). These basic changes, orchestrated by both public and private organizations, now shape human life in unprecedentedly subtle yet serious ways.

The global pandemic that began in 2019 and spread in waves of contagion throughout the world was met with increased modes of surveillance that accentuated the vexing issues of data circulation. These were already the stuff of government commissions, academic research, company policy, and privacy and data protection regimes the world over. But now they presented themselves as even more troubling conundrums. While one might well be skeptical about the "security theater" and "terrorist threat" scares spawned by 9/11, COVID-19 was a palpable peril. Many thousands of ordinary people got horribly sick and died in many countries - and at the time of writing, are still being infected and, all too often, dying. The dismal toll does of course affect some population groups - predictably, the already disadvantaged and vulnerable - more than others, but it is nevertheless the case that millions more people around the world are at serious risk than were ever affected by terrorism.

At the same time, the situation also catalyzed the accelerated adoption of many new technologies. Consumer and business digital adoption skyrocketed (McKinsey 2020) with leaps of speed and scale. Online shopping and cashless transactions grew faster than anyone anticipated, while communication platforms such as Zoom grew from 10 million users in December 2019 to 300 million users by October 2020. In this context, Shoshana Zuboff's (2019) 
analysis of surveillance capitalism becomes strikingly relevant. Platforms are driven by the impulse to collect, analyze, and act upon such everyday data, exponentially. Beyond the directly commercial context, schools and universities switched, when "necessary," to remote learning, complete with apps for everything from checking attendance to policing exams, and many employees still lucky enough to have jobs remained at home to work-all the while monitored by newly installed software. And of course, in obvious areas such as health, doctors switched rapidly in many countries to online consultations. The public health innovations were just another aspect of this generalized digital shift. However, while Zuboff's (2019) primary concern is how behavioral manipulation constrains what she sees as "autonomy," this hardly touches upon the urgent questions of how surveillance capitalism also magnifies socioeconomic inequalities, compounding systemic injustice.

The most immediate effects of the pandemic are those relating to healthcare and the imperative to reduce the risk of infection and its spread. A central conundrum is that those at risk wish to feel safe, but the proffered "solutions" are often ones that themselves carry risks. Contact-tracing, for instance, which in many cases offers to alert the users of an app when they have been close to an infected person, is replete with such contradictions. Systems may be either centralized, as the initial program in the UK, or related ones in China and Israel-Palestine, or decentralized, the latter often taking advantage of the Google-Apple API, offered so that health departments may create their own apps. Decentralized systems also include the European Decentralized Privacy-Preserving Proximity-Tracing protocol used in several countries. More data may be acquired through centralized systems, deemed useful for risk modeling and analysis, but critics object that without clear limits, once in government hands, those data could easily be used for other purposes. Beyond privacy and security concerns are important ethical and justice issues (Kitchin 2020; Muller 2020; Scassa et al. 2020).

Such issues, beyond what might be covered by privacy or data protection law, include simple failure to do the right thing, such as warning citizens about the limitations of digital tracking for contact-tracing. They can easily produce false positives - for instance if carried down a grocery store aisle. Again, the Bluetooth versions may have insufficient uptake, thus reducing their reliability. On a wider level, the use of contact-tracing apps may be used by employers to prevent workers from returning to work or, if used as "COVID passports," could undermine their "non-mandatory" status. The lack of access to such apps by those without cellphones could exacerbate other forms of inequality.

These kinds of complications, common to surveillance in the twenty-first century, have been widely accentuated during the global pandemic. Extensive public-private cooperation, for example, is visible in just about every jurisdiction, whether authoritarian or democratic. Chinese COVID-19-inhibiting initiatives, for instance, feature major corporations such as Alipay, which runs 
the major contact-tracing app with its three-color "Health Code" scheme but is also answerable to the State Council. Indeed, the initiative with Alipay is also seen as a test-run for China's "Social Credit" schemes, set up, paradoxically, with precisely the aim of ensuring trust in a society that lacks Westernstyle credit cards. Critical discussion of these issues was sparked on Weibo (roughly the Chinese equivalent of Twitter), suggesting that much mistrust exists regarding the responses to the pandemic (Lin 2020).

The politics of trust and transparency are also observable. For example, South Korea was frequently cited in contrast to the Chinese case with respect to trust in government COVID-19 schemes. Much was made-by UNESCO for example-of the "openness and transparency" of South Korea's response to the rapid spread of the virus in that country (UNESCO 2020). It is interesting that the government's greater "transparency" was in response to complaints about damaging government secrecy during the MERS pandemic of 2015, when little was reported about virus hotspots. In 2020, after an explosive early outbreak, testing and tracing were implemented much more rapidly, plus public mapping in which citizens could check the movements of patients identified only by gender and age, and even see whether their homes were disinfected or if they were wearing masks (Thompson 2020).

Public trust in government is crucial to the effective working of digital systems established to counteract the pandemic (Ball et al. 2018), and such trust is based on the perceived trustworthiness of the government departments concerned. Furthermore, such trustworthiness must depend on the keeping of commitments, a feature of trust that applies in both interpersonal and institutional contexts (Hawley 2012). Some governments lost citizen trust, at least for a time, as was the case in Mexico in November 2020, when a program using QR swiping for contact-tracing was announced - including the fact that participation would be mandatory. This lacked democratic process, to which Mexico is officially committed. The former Data Protection Commissioner tweeted her disapproval, asking citizens to resist, and just before the rollout the government back-pedaled, stating that the initiative was voluntary (Martínez 2020). But of course, such episodes are not merely products of the pandemic. They relate to much longer-term shifts in patterns of governing and especially to the democratic deficits seen in contemporary populism and neoliberal practices and policies.

Many issues have arisen also concerning transparency. Transparency may be demanded by citizens and pressure groups but may also be imposed by the powerful. As Shaul Duke (this volume) notes, the tensions between "imposed" and "voluntary" transparency are profound and are worked out in a range of moves and counter-moves in the case he discusses-Israel/ Palestine. During the pandemic, Israel required Shin Bet-the security agency normally involved in checking on Palestinian "terrorism"- to manage the country's contact-tracing system. Though critical questions 
about civil liberties were raised about this in Israel and internationally, Shin Bet continued to run the contact-tracing system until March 2021 (Amit et al. 2020). This is hardly reassuring for those who see Shin Bet as a key means of minimizing Palestinian self-determination through its debilitating suspicion of both Israeli Arabs and Palestinian communities in the West Bank and Gaza. Transparency was in fact missing from the start, as the Shin Bet contact-tracing system was set up after an overnight cabinet meeting, thus bypassing parliamentary approval.

Both transparency and trust also have to be placed in a larger context, however - that of the rapidly expanding world of reliance on digital infrastructures. While the decades following World War II saw the application of computing and communication technologies to bolster and support surveillance activities, both commercial and governmental, the present stage of digital development means that the infrastructures themselves are deeply surveillant. The platform companies and surveillance capitalism represent this shift, in which value is located in the metadata generated by the everyday use of social media in particular and the internet in general. Transparency is seriously lacking among the platform companies; even when Facebook's Mark Zuckerberg faces high-level public questioning he refuses to acknowledge what Facebook routinely does with its users' data. And as Twitter's Jack Dorsey admitted at the October Congressional hearings, "We realize we need to earn trust more, we realize that more accountability is needed, to show our intentions and show our outcomes" (Romm et al. 2020).

\section{Understanding trust and transparency sociologically}

The concept of transparency has been debated in relation to the digital realm for several decades. It is unlikely to subside any time soon. Over time, it has taken wildly different forms, from the bright optimism of David Brin's (1998) The Transparent Society to Byung Chul Han's (2015) gloomy pessimism in The Transparency Society. Each of these books deals mainly with social transparency in the context of the putative loss of privacy in contemporary society. Brin argued that the quest for government-protected privacy is ultimately futile and that worries about growing surveillance could be assuaged by giving everyone the means of surveillance. This is an old argument, also sometimes used by those who optimistically engage in sousveillance or "watching from below."

But as technology critic Bruce Schneier (2008) observes, Brin discounts the already existing power differences between the parties involved, which place strong limits on hopes for transparency understood in this way. This relates closely with the arguments often made about inequalities associated with surveillance as "social sorting," especially in a big data context (Lyon 2003, 2007; Eubanks 2018). The power differentials are clear in a world where surveillors increasingly score and rank the populations on whom they have data, using 
complex and inaccessible data analytics, without revealing how that process occurs or that its effects are consequential on those groups (Lyon 2014).

Byung Chul Han, on the other hand, while also acknowledging what he views as the diminution of private life, maintains that easily obtainable information means that transparency - that is, primarily, of those targeted by surveillance - creates a society of control, not of trust. Politics becomes increasingly short-term, with little sense of responsibility for the future. He sees this worsening with the COVID-19 pandemic, arguing that the state of exception engendered by the pandemic will be made permanent through the expanded use of digital tools against the coronavirus. Thus, the isolating tendencies of pandemic controls will strengthen the capitalist state (Han 2020).

Beyond such debates, in which participants often seem to talk past each other, it makes sense to consider some more specific problems with transparency as a goal among those who wish to increase democratic participation in digital times. One astute critic is David Pozen, who shows how easily the word transparency can be - and is - subverted in contemporary political discourse. While many still cling to the concept as a critically important aspect of good governance, or of data protection and policy, "it is increasingly suspected of facilitating antiregulatory or neoliberal agendas and of undermining the very values it is meant to promote" (Pozen 2019: 326; see also Viola this volume). Pozen very sensibly notes that as a concept, transparency is not coherent and thus that different and opposing views of its usefulness are bound to proliferate (see also Bjorkland, this volume). And he argues that a "sociological turn" is required to examine the historical, legal, cultural, and other contexts in which transparency concepts are developed and used.

Pozen quotes Darin Barney, who insists that transparency is never a "thing" but a social process, a means, not an end (Pozen 2019: 327). This is why sociological clarity is required. Human flourishing, or the flourishing of the earth itself, are ends, within which we may locate, in the present context, derived goals such as data justice. Transparency, on the other hand, is merely a means to such ends and has to be evaluated in each context for its contribution to human and social benefit. If, for instance, the opacity of the terms of service advertised by platform companies could be reduced, then the transparency of the provider to the user would be enhanced. But for this to serve genuine goals, other requirements, such as that users know how to respond to the information to which they now have access (see e.g. Raab 2012a), would have to be met. But greater platform transparency is only one limited step toward proper accountability. The latter has been developed more fully during the present century and has been given teeth within some data protection and human rights contexts (Raab 2012b). But neither transparency nor accountability in themselves could bring anything like a satisfactory condition of data justice into being. Why? Because if data justice means ensuring how people are made visible, represented, and treated, using data, is appropriate and fair, 
then merely to see more clearly how users are unfairly dealt with will not contribute much to desirable outcomes.

So, can transparency contribute to more trust in government, as was frequently suggested in the later twentieth century? Again, it depends. As Matthew Hall (this volume) eloquently argues, the act of publicizing power can itself have chilling effects. As he observes, the very fact that one could be harmed by surveillance may damage our freedom as citizens; such domination is a present threat. Theoretically, at least, Pozen is correct to say that the transparency-trust relationship is not self-evident (see also Bjorkland, this volume). But he also pleads for careful empirical analysis of the social situations in which transparency is sought, analysis that is highly attentive to context. The kinds of research that are required for a proper understanding of transparency in relation to rapidly expanding surveillance capitalism would do well to heed the suggestions made by Pozen. They are highly germane to the goals of any study of transparency, especially as it affects trust. As he concludes, "sociological inquiry, broadly conceived, gives our best hope for developing a deep understanding of transparency policies and their many and varied impacts" (Pozen 2019: 330).

\section{What conditions are required for human flourishing?}

As noted earlier, all too often, the weight of technological development and public policy pulls questions about surveillance down to the level of technocratic and deterministic criteria. There are many examples of how this happens. One is that the increasing range of public-private partnerships has made it more difficult to demand full accountability from corporations, which are sometimes seen as extensions of government activity rather than as entities subject to rules, regulations, and laws. Beyond this, of course, is the massive power of today's giant tech companies - the platforms in particular-that seems to lend them a sense of invincibility and immunity from criticism. Then, as they are tech companies, they depend on computing scientists and software engineers, who - despite some shining contrary examples - often dissociate themselves from the social contexts and consequences of their work and disengage from the politics of their endeavors (Möllers forthcoming).

Intellectual and practical work is needed to reverse the apparent guiding principle of much technological innovation, which is that human beings should constantly adapt themselves to the new. This chapter urges, rather, consideration of ways in which technologies could be shaped to truly human ends. Thus, in our present context, for example, the development of surveillance systems, devices, and apps should be guided by criteria whose shorthand here is "human flourishing." And if that sounds like a rather vague term, substantive content follows. It is deliberately broad, denoting a cluster of virtues and goals. 
Of course, human flourishing is seen in diverse ways around the world, but many - perhaps classically, Aristotle - have seen such flourishing as dependent on living life with others, with people helping one another to develop virtues - good habits - which, as they continue to be practiced, contribute to love and justice. Such ideas are common to the world's religions, especially the Abrahamic: Judaism, Christianity, and Islam. As Miroslav Volf (2017) argues, such religions are inherently globalizing, and in an intensively globalized world, they continue to offer themes to guide contemporary societies. Love and justice are two pursuits related to flourishing, and in the context of surveillance they can be given specific aims - to an ethics of care with data on the one hand and to data justice on the other. One way of seeking these would be to ensure specific forms of transparency from those who surveil, such that they could demonstrate their willingness to be accountable to others, particularly when the plight of vulnerable population groups is obscured by the data (Taylor 2020). It would also contribute to trust if they were thus shown to be open to assessment. But this is only a first step to the goal, not the destination.

What social, technological, and political conditions might help promote human flourishing? Flourishing is more than health or security; it comprises a complex amalgam of varying features (Volf 2017). Nor is it appropriate to reduce flourishing to autonomy. There is a need to go beyond Zuboff's excellent work on surveillance capitalism here. Her target - not inappropriatelyis the manipulation and behavior modification sought by Google and other platforms that emulate Google (Zuboff 2019). But, firstly, claims about autonomy can easily be reduced to an individualistic level and thus to a denial of the intrinsic sociality of humanness. And, secondly, the shaping of personal behaviors is not the only product of surveillance capitalism, which also systematically reproduces and reinforces social difference and disadvantage. Thus, a key aim of any desire to recalibrate the current mode of prediction to quite different ends would be rather to promote and struggle for "data justice" (Taylor 2017).

For Taylor, data justice goes beyond current data practices, which tend to be driven by technical, governmental, and commercial goals rather than social ones. Data-driven discrimination is widespread and relatively unimpeded by law or regulation. The root of the problem is that algorithms are constructed that make people visible in particular ways and that visibility is highly consequential for life chances and choices. To seek data justice is to demand fairness in the ways that people are made visible, represented, and treated as they continuously produce data. Doing this leads to the discovery of ethical paths through a datafying world. For Taylor, international data justice involves (in) visibility, (dis)engagement with technology, and antidiscrimination (Taylor 2020). Transparency and accountability are crucial here, especially in relation to the public-private interface, which today is a central issue in surveillance. 
Governments employ few data scientists and generally rely on corporate bodies to provide such assistance.

Taking this further, many grassroots concerns and activities are evidence of social involvement and the search for local and global person-and-planet practices and orientations. In terms of technological involvement, movements to reinscribe social responsibility in technical education, reengaging computing and software professionals with the wider purposes of their expertise, is a vital contribution. Sara Degli-Esposti and David Arroyo (this volume) make an excellent case for trust-as-care, as opposed to mere control, which also speaks strongly to the matter of computing and software education. This can be reinforced, in the pandemic context, with Taylor's (2020) call for an ethics of care over and against the dominant utilitarian calculations, especially in countries where neoliberalism has taken root. This places emphasis on the collective rather than the population. People, with their unequal positions, are the focus.

Such social awareness may be complemented with more properly political activities in the quest for data justice - which also questions utilitarian calculation - and in the search, for instance, for ways of giving citizens the opportunity to help decide the rules of transparency (Hall, this volume). In addition, Verde Garrido (this volume) also insists that surveillance overreach, as exposed by Edward Snowden, requires citizens not to trust certain government agencies. These general orientations also have to be considered in the context of local historical cultural conditions. These include not only the massive and now long-term influence of tech giants based in California's Silicon Valley, but also, today, the huge influence of China and, increasingly, India. While the US platforms still affect millions in many parts of the globe, the influence of the newer digital economies of China and India have farreaching impacts in emerging countries of the Global South in particular (Chakrovorti 2018).

\section{Mobilizing publics, from grassroots to global}

How can human agency and human flourishing be asserted in an age of surveillance? This appears as an unattainably high-level question at the best of times, but especially during a global pandemic. Yet a moment's reflection on the alternatives may place this aim in a better, and more realistic, light. Platform and related companies in many countries are frequently monopolistic, hugely powerful in their control of resources, markets, and employees, and arrogantly confident that they can do a better job of governing than democratically elected officials. Although much surveillance is carried out by government departments, security agencies, and the police, their activities are very often dependent on systems, software, and data originating in those corporations. The surveillance systems that have evolved under tech 
company guidance exude utilitarian, technocratic, and "tech-solutionist" approaches.

There currently seems to be little enthusiasm for transparency among the leading players of the platform world. Their multibillionaire CEOs, such as Jeff Bezos, formerly at Amazon, and Mark Zuckerberg, at Facebook, show no signs of opening their corporate activities to scrutiny, any more than Sundar Pichai at Google - the company credited with creating surveillance capitalism-does. In the United States, Facebook's reputation has slipped significantly, mainly due to a lack of user trust in its handling of personal information, while Microsoft holds a high place and Amazon likewise-no doubt credited with keeping people supplied with the goods no longer available in brick-and-mortar stores at the start of the pandemic (Verge 2020). At the same time, the Verge (2020) survey supported earlier findings by Pew researchers that around half the US population believes that the big platforms do indeed require more government regulation (Smith 2018). But will governments step up and actually challenge the platforms? Former UK Information Commissioner Elizabeth Denham stands out for her challenge to Facebook after the Cambridge Analytica scandal in 2018. But the maximum fine she could levy was GBP500,000 - a drop in a bucket for Facebook. This is a critical question that will have to be faced head-on in the coming years, if trust is to be restored.

How can the public be mobilized to reflect and deliberate on these issues? Post-Snowden, many have been retreating even further from public debate. And in some countries, of course, meaningful public debate has been muted by rising populist authoritarianism and nationalism. In Europe and the United States, some public debate has been growing, mostly in relation to the apparent unreliability of platforms and their unwillingness to listen to criticism - think Facebook, Amazon, Google, but also Airbnb and Uber. However, some security surveillance activities are still under scrutiny (e.g. Lyon and Murakami Wood 2020).

Of course, it may well also be possible to add surveillance trust-andtransparency concerns to other public issues. The Black Lives Matter movement is an obvious case in point in the northern hemisphere, as that cannot but be associated with police surveillance technologies, particularly body cameras and facial recognition technologies, in which data justice is manifestly lacking. Specific data-justice-promoting proposals relating to COVID-19 systems include data trusts (Dawson 2020) and distributed ledger technology (Demos Helsinki 2020). In addition, environmental and green concerns have to be considered in relation to the increasingly heavy energy requirements for server farms to service the internet, and these can be tied in with surveillance and data justice concerns (cf. Deibert's (2020) Massey Lectures emphasizing civil society).

A final, crucially important argument is prompted by the currently dominant feature of the internet, in its platform and social media aspects. The 
culture of surveillance manifests a multiplicity of modes of online involvement, in which data politics (Bigo et al. 2019; Lyon 2019) is increasingly important and within which data justice becomes increasingly paramount (Taylor 2017). If agency is to be recovered in this area, it will come from those actively engaged with the internet, whose involvement is constructively political. The attitude of the platform companies, as Zuboff (2019) often observes, is that their activities are inevitable and their consequences unavoidable, and behaving as if such doctrines are true will indeed undermine agency. But the evidence of much online activism (cf. Verde Garrido, this volume) gives that doctrine the lie. Indeed, within the internet and social media itself many work to demonstrate that care and justice should govern both our considerations of transparency and the pressure to create new grounds for trust in the world of the digital.

\section{References}

Amit, Moran, Heli Kimhi, Tarif Bader, Jacob Chen, Elon Glassberg, and Avi Benov. 2020. "Mass Surveillance Technologies to Fight Coronavirus Spread: The Cases of Israel." Nature Medicine. 26(August): 1160-1169, www.nature.com/articles/ s41591-020-0927-z.pdf?origin=ppub.

Ball, Kirstie, Sara Degli Esposti, Sally Dibb, Vincenzo Pavone, and Elivira Santiago-Gomez. 2018. "Institutional Trustworthiness and National Security Governance: Evidence from Six European Countries." Governance. 32(1): 103-121.

Bigo, Didier, Engin Isin, and Evelyn Ruppert. 2019. Data Politics: Worlds, Subjects, Rights. London: Routledge.

Brin, David. 1998. The Transparent Society. New York: Perseus.

Chakravorti, Bhaskar. 2018. "Competing in the Huge Digital Economies of China and India." Harvard Business Review. November 6, 2018, https://hbr.org/2018/11/ competing-in-the-huge-digital-economies-of-china-and-india/.

Dawson, Philip. 2020. "COVID-19 Tracking Data Should Be Managed the Way Data Trusts Are." Policy Options, April 20, 2020, https://policyoptions.irpp.org/ magazines/april-2020/covid-19-tracking-data-should-be-managed-the-way-datatrusts-are/.

Deibert, Ron. 2020. ReSet: Reclaiming the Internet for Civil Society. Toronto: Anansi.

Demos, Helsinki. 2020. "Tech vs COVID-19: Transparency and Trust Go to the Heart of Public Power.” June 1, 2020, www.demoshelsinki.fi/en/2020/06/01/letter-tech-vscovid-19-transparency-and-trust-to-the-heart-of-public-power/.

The Economist, 2020. "Countries Are Using Apps and Data Networks to Keep Tabs on the Pandemic ... and also, in the Process, Their Citizens." March 28, 2020, www. economist.com/briefing/2020/03/26/countries-are-using-apps-and-data-networksto-keep-tabs-on-the-pandemic/.

Eubanks, Virginia. 2018. Automating Inequality: How High-Tech Tools Profile, Police and Punish the Poor. New York: St Martin's Press.

French, Martin, and Torin Monahan. 2020. "Dis-ease Surveillance: How Might Surveillance Studies Address COVID-19?” Surveillance \& Society 18(1): 1-11.

Han, Byung Chul. 2015. The Transparency Society. Stanford: Stanford University Press. 
Han, Byung Chul. 2020. "Los países asiáticos están gestionando mejor esta crisis que Occidente." El Pais, https://elpais.com/ideas/2020-03-21/la-emergencia-viraly-el-mundo-de-manana-byung-chul-han-el-filosofo-surcoreano-que-piensa-desdeberlin.html. English translation available at https://www.readingthechinadream. com/byung-chul-han-coronavirus.html.

Hawley, Katherine. 2012. Trust: A Very Short Introduction. Oxford: Oxford University Press.

Kelley, Jason. 2020. "Governments Must Commit to Transparency During the COVID-19 Crisis." March 20, 2020, www.eff.org/deeplinks/2020/03/governmentsmust-commit-transparency-during-covid-19-crisis.

Kitchin, Rob. 2020. "Using Digital Technologies to Tackle the Spread of Coronavirus: Panacea or Folly?" Maynooth University, https://progcity.maynooth university.ie/wp-content/uploads/2020/04/Digital-tech-spread-of-coronavirus-RobKitchin-PC-WP44.pdf.

Lin, Liza. 2020. "China's Plan to Make Permanent Health-Tracking on Smartphones Stirs Concern." The Wall Street Journal, May 25, 2020, www.wsj.com/articles/ chinas-plan-to-make-permanent-health-tracking-on-smartphones-stirs-concern11590422497.

Lyon, David. 2003. Surveillance as Social Sorting: Privacy, Risk and Digital Discrimination. London: Routledge.

Lyon, David. 2007. Surveillance Studies: An Overview. Cambridge: Polity Press.

Lyon, David. 2014. "Surveillance, Snowden and Big Data: Capacities, Consequences, Critique." Big Data \& Society. July-December: 1-14. https://journals.sagepub.com/ doi/pdf/10.1177/2053951714541861.

Lyon, David. 2019. "Surveillance Capitalism, Surveillance Culture and Data Politics." In Data Politics: Worlds, Subjects, Rights, edited by Didier Bigo, Engin Isin, and Evelyn Ruppert, 64-78. London: Routledge.

Lyon, David. 2021. Pandemic Surveillance. Cambridge: Polity Press.

Lyon, David, and Murakami Wood, David. 2020. Security Intelligence and Surveillance in the Big Data Age: The Canadian Case. Vancouver: University of British Columbia Press.

Martínez, Laura. 2020. "Contact-Tracing and Personal Data Protection Face-Off in Mexico City." Slate, https://slate.com/technology/2020/11/mexico-city-qr-codecontact-tracing-program-coronavirus.html.

McKinsey. 2020. "How COVID-19 Has Pushed Companies over the Tipping Point and Transformed Business Forever." (Report), www.mckinsey.com/business-functions/ strategy-and-corporate-finance/our-insights/how-covid-19-has-pushed-companiesover-the-technology-tipping-point-and-transformed-business-forever/.

Möllers, Norma. Forthcoming. A Culture of Disengagement: Computer Science and the Question of Justice in Algorithms. Cambridge: MIT Press.

Muller, Bertie. 2020. "Tracking COVID-19 Effectively Rests on Transparency." Techerati, www.techerati.com/features-hub/opinions/tracking-covid-19-effectivelyrests-on-transparency/.

Pozen, David. 2019. "Seeing Transparency More Clearly." Public Administration Review. 80(2): 326-331.

Raab, Charles. 2012a. “The Meaning of 'Accountability' in the Information Privacy Context.” In Daniel Guagnin et al., eds. Managing Privacy Through Accountability. London: Palgrave-Macmillan. 
Raab, Charles. 2012b. "Regulating Surveillance: The Importance of Principles." In Kirstie Ball, Kevin Haggerty, and David Lyon, eds. The Routledge Handbook of Surveillance Studies. London: Routledge.

Romm, Tony, Rachel Lerman, Cat Zakrzewski, Heather Kelly, and Elizabeth Dwoskin. 2020. "Facebook, Google, Twitter CEOs Clash with Congress in PreElection Showdown." The Washington Post, www.washingtonpost.com/technology/ 2020/10/28/twitter-facebook-google-senate-hearing-live-updates/.

Roussi, Antoaneta. 2020. "Resisting the Rise of Facial Recognition." Nature. November 18, www.nature.com/articles/d41586-020-03188-2.

Scassa, Teresa, Jason Millar, and Kelly Bronson. 2020. "Privacy, Ethics and ContactTracing Apps.” In Colleen M. Flood, Vanesssa MacDonnell, Jane Philpott, Sophie Thériault, and Sridhar Venkatapuram, eds. Vulnerable: The Law and Politics of COVID-19, Chapter C-2. Ottawa: University of Ottawa Press.

Schneier, Bruce. 2008. "The Myth of the Transparent Society.” Wired, March 6, 2008, www.schneier.com/essays/archives/2008/03/the_myth_of_the_tran.html/.

Smith, Aaron. 2018. "Public Attitudes Toward Technology Companies." Pew Research, www.pewresearch.org/internet/2018/06/28/public-attitudes-towardtechnology-companies/.

Stoddart, Eric. 2021. The Common Gaze: Surveillance for the Common Good. London: SCM Press.

Taylor, Linnet. 2017. "What is Data Justice? The Case for Connecting Digital Rights and Freedoms Globally." Big Data \& Society. July-December: 1-14, https:// journals.sagepub.com/doi/pdf/10.1177/2053951717736335/.

Taylor, Linnet. 2020. "The Price of Certainty: How the Politics of Pandemic Demand an Ethics of Care." Big Data \& Society. July-December: 1-7, https://journals. sagepub.com/doi/pdf/10.1177/2053951720942539/.

Thompson, Derek. 2020. "What's Behind South Korea's COVID-19 Exceptionalism?" The Atlantic, www.theatlantic.com/ideas/archive/2020/05/whats-south-koreassecret/611215/.

UNESCO. 2020. "How the Republic of Korea Flattened the COVID-19 Curve: Openness, Transparency and Democracy." https://en.unesco.org/news/howrepublic-korea-flattened-covid-19-curve-openness-transparency-and-democracy.

Verge. 2020. "Tech Survey.” www.theverge.com/2020/3/2/21144680/verge-tech-survey2020-trust-privacy-security-facebook-amazon-google-apple.

Volf, Miroslav. 2017. Flourishing: Why We Need Religion in a Globalized World. New Haven: Yale University Press.

Zuboff, Shoshana. 2019. The Age of Surveillance Capitalism. New York: Public Affairs. 